\title{
RAMOS, Danilo Paiva. Círculos de coca e fumaça. São Paulo: Hedra, 2018.
}

\section{Diego Rosa Pedroso}

Universidade de São Paulo

"Círculos de coca e fumaça", publicação da tese de doutorado de Danilo Ramos, resultado de seus anos de pesquisa etnográfica no alto rio Negro, noroeste da Amazônia brasileira, constitui contribuição de grande importância para a literatura antropológica. O livro é uma etnografia das práticas do povo indígena Hupd'äh relativas à coca, com particular atenção a certa forma relacional constante da sociabilidade desse povo: as rodas de coca.

Dada a riqueza e densidade da descrição etnográfica desenvolvida por Danilo Ramos, uma resenha que tente tratar de modo igual o conjunto dos capítulos está fadada ao fracasso. Assim, darei mais atenção ao contexto da pesquisa e ao lugar dos Hupd'äh na configuração social regional, os quais são apresentados logo na introdução e no primeiro capítulo. Passarei brevemente pelos capítulos subsequentes, a título de convite à leitura, arrematando com uma apreciação final do livro como um todo.

A pesquisa parte da constatação de que a literatura etnográfica regional disponível, de modo geral, não deu atenção a determinados aspectos da vida social dos povos indígenas do alto rio Negro. Danilo Ramos chama a atenção especificamente para as rodas de coca, as quais parecem ter sido relegadas a certa invisibilidade, aparentemente por conta da constância na realização dos encontros noturnos onde tais rodas acontecem, diante daquelas que seriam as práticas rituais e extracotidianas por excelência, o Jurupari e o Dabucuri. As rodas de coca foram, assim, relegadas a um campo pouco descrito das ações cotidianas. Danilo Ramos, com sua pesquisa, busca mostrar a centralidade desse modo de ação para os Hupd'äh.

O livro está organizado em duas partes, com quatro capítulos cada, além da introdução e das considerações finais. Na primeira parte, "Coca e fumaça", o autor descreve as rodas de coca, expondo ao leitor a acima referida invisibilidade que tal prática ocupou na literatura disponível; narra uma viagem que fez a Serra Grande, mostrando como tais deslocamentos implicam processos de educação da atenção; e, por fim, descreve a sequência de ações das rodas de coca, bem como o lugar central do tabaco nessas rodas para as práticas de benzimento. Na segunda parte, "Círculos e caminhos", Danilo Ramos aprofunda as articulações entre os encontros noturnos e as viagens pelos caminhos, e perpassa ao longo dos quatro capítulos temas como o nascimento e os cuidados envolvidos com a criança e os pais, a caça, os rituais de Dabucuri e Jurupari, e o lugar das viagens a São Gabriel da Cachoeira para os Hupd'äh.

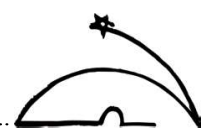


Na introdução, Danilo Ramos narra sua chegada a São Gabriel da Cachoeira e a preparação da viagem a comunidade hupd'äh. Segue-se a descrição do percurso pelos rios Negro, Uaupés e Tiquié, até a chegada à comunidade de /Tat-Dëh/ ("Taracuá-Igarapé”), situada em território hup às margens do igarapé de mesmo nome, afluente do rio Tiquié, região interfluvial desse rio e o Papuri, onde o autor permaneceu entre os anos de 2009 e 2012, e na qual viviam então aproximadamente 202 indivíduos, distribuídos em vinte e seis casas.

Mas quem são os Hupd'äh? Uma caracterização desse povo é apresentada também na introdução: a estrutura social hup tem como seus segmentos básicos de constituição e diferenciação os clãs agnáticos. Hoje, há aproximadamente 25 clãs exogâmicos de descendência patrilinear. Cada clã possui um conjunto específico de nomes, mitos e cantos através dos quais são narrados os eventos de criação e se constitui um senso de pertencimento e identidade. Em contraste com outros povos da região, sobretudo grupos da família linguística Tukano Oriental, o sistema matrimonial hup dá-se segundo a endogamia linguística e a exogamia clânica. Segundo Danilo Ramos, esses traços aproximam os Hupd'äh de povos como os Yuhupdëh, Nadëb, Dâw, Kákwa e Nukák, permitindo que fossem designados pela literatura etnológica da região como povos maku.

O contato com os povos ditos maku teve início com as frentes de colonização desde o século XVIII, mas foi apenas nas décadas de 1960 e 1970 do século XX que os missionários salesianos iniciaram atividades mais intensas visando à evangelização e à escolarização dos Hupd'äh. A literatura etnológica acerca desses povos, por sua vez, apesar do longo tempo desde o contato, não é muito extensa. Dentre os trabalhos existentes, destacam-se os de Peter Silverwood-Cope, primeiro estudo etnográfico detalhado sobre um grupo maku, os Bara-Maku (Kákwa), realizado no final da década de 1960. Segundo Danilo Ramos, a complexidade revelada pela pesquisa desse antropólogo inglês apontou a necessidade da revisão da categorização desses povos como sendo caçadores e coletores nômades muito primitivos que, de acordo com certa imagem que o autor mostrará no primeiro capítulo ser proveniente de Koch-Grünberg, vinham sendo assimilados e escravizados por povos agricultores invasores. Depois de Peter Silverwood-Cope, seguiram-se as pesquisas de Howard Reid sobre os Hupd'äh, de Renato Athias sobre as relações entre os Hupd'äh e Tukano, de Jorge Pozzobon sobre diversos povos maku e, mais recentemente, o trabalho de Pedro Lolli sobre os Yuhupdëh. Desses, apenas o trabalho de Reid apresenta uma monografia extensa sobre os Hupd'äh.

O olhar de Danilo Ramos, ao ler essa literatura, se dirige sobretudo para as narrativas e ritos, chamando sua atenção o lugar menor dado a esses temas. Assim, narrativas e ritos aparecem nas referidas obras como "elementos descritos para a composição de um quadro geral desses povos, surgindo, geralmente, em capítulos destinados à cosmologia ou em meio à descrição da organização social desses povos" (RAMOS, 2018: 35). Diante desse quadro, tomando como referência os encontros noturnos enquanto uma forma de interação social específica, articulada aos movimentos das viagens, o trabalho que Danilo Ramos desenvolveu procura "delinear o modo como narrativas e andanças geram importantes condensações rituais que entrelaçam rodas, caminhos e 
paisagens como campos de percepção e ação vividos mutuamente pelas pessoas hup" (Ibid.). Dito de outra maneira, o tema central da pesquisa é a percepção de que as rodas de coca se constituem como uma forma constante de interação, central para os fazeres mítico e xamânico, a partir dos quais se estabelecem relações fundamentais no universo hup, e que "seus movimentos fazem-nos passar por lugares onde eventos míticos ocorreram, visitar paisagens habitadas por seres diversos e praticar ações rituais no alto de morros como a Serra Grande" (Id.: 26)

Foi ao longo de sua pesquisa que o autor entendeu que os encontros noturnos podem ser vistos como um modo de ação que permite aos participantes constituírem percursos de observação a partir de seus próprios movimentos em meio às palavras sopradas dos encantamentos e aos passos trilhados pelos caminhos que atravessam a floresta. As rodas de coca passaram a ser vistas por Danilo Ramos como performances onde, em meio à sequência dos encontros e viagens, "ocorrem múltiplas condensações rituais, tornando determinados gestos, posturas, palavras e substâncias fundamentais para a interação com todos aqueles com quem os Hupd'äh partilham paisagens e saberes" (Id.: 27).

$\mathrm{Na}$ introdução, portanto, o leitor é apresentado ao tema da etnografia, ao povo com o qual o autor trabalhou, à literatura disponível, e ao referencial teórico. Nota-se já na introdução, o que será reforçado ao longo dos oito capítulos: a importância sobretudo de certos conceitos de Tim Ingold sobre paisagem, percepção e percursos de aprendizagem. A tese investe no cotidiano, oferecendo uma fenomenologia da vida social Hupd'äh, perspectiva teórica e analítica pouco explorada na literatura etnológica regional. Assim, outro mérito a ser destacado no trabalho de Danilo Ramos é seu pluralismo teórico, reunindo autores como, além do já citado Ingold, a antropologia relacionalista de Peter Gow, com destaque sobretudo para o modo produtivo como operacionaliza a noção de mundo vivido desse autor, a chamada antropologia da performance de Victor Turner, certos procedimentos estruturalistas de Lévi-Strauss, e a teoria do ritual de Houseman e Severi, que funcionam em concerto de modo a aproximar o leitor da complexidade do mundo Hupd'äh, como o próprio Danilo Ramos reconhece:

\footnotetext{
a percepção dos encontros noturnos como contextos que associam os fazeres mítico, xamânico às andanças, a partir de uma forma relacional particular, que articula modos de ação, exige que diferentes referenciais teóricos sejam mobilizados para a descrição e interpretação das múltiplas dimensões das rodas de coca (Id.: 39).
}

O primeiro capítulo "Viajantes", apresenta a viagem de Theodor Koch-Grünberg à região do alto rio Negro em 1903. Durante essa viagem, Koch-Grünberg fez o reconhecimento do rio Tiquié, com a esperança de entrar em contato com os Maku, mas não conseguiu chegar as aldeias dessa população indígena, entrevistando aqueles que se encontravam nas aldeias tukano. Como resultado desse trabalho, Koch-Grünberg publicou o artigo "Die Maku" (1906), onde apresenta uma visão bastante distorcida desses povos. Como explicar a visão preconceituosa de Koch-Grünberg 
no artigo de 1906? De que modo esse artigo influenciou estudos posteriores e, como a partir de "Die Maku" o tema da mobilidade passa a ser fundamental para a interpretação do modo de vida dos Maku? Essas são as questões que Danilo Ramos explora no primeiro capítulo de seu livro.

Segundo o autor, aos olhos de Koch-Grünberg, a animalidade dos Maku passava pela percepção de seu nomadismo, pelo modo de fala, pela feiura da aparência física e pelo fato de serem os primeiros habitantes da região, posteriormente conquistados, assimilados e/ou escravizados por civilizações mais avançadas (Id.: 50). O modo como Koch-Grünberg descreve os Maku é resultado, explica o autor, da impossibilidade de contato direto com comunidades maku e da também impossibilidade de comunicação direta com os indivíduos maku que se encontravam junto aos Tukano, o que fez com que o pesquisador alemão tomasse como referência as falas e visões de pessoas de outras etnias para elaborar seus apontamentos sobre os Maku.

Tal como na imagem constituída pelos Tukano, é também através da ênfase nos aspectos de um princípio global de mobilidade dos Maku que o etnólogo alemão vai concebendo sua representação. A partir disso, o que Koch-Grünberg propõe é "uma espécie de 'teoria da dominação', que encontra nas oposições entre agricultores versus caçadores-coletores e nômades versus sedentários a base para a interpretação das relações entre esses diferentes povos como relações de 'senhor e escravo"" (Id.: 53). Dito de outro modo, ouvindo e reproduzindo certa visão dos Tukano, Desano e Tuyuka sobre os Maku, Koch-Grünberg estava "gestando uma forma de olhar, um determinado modo científico e evolucionista de observar os povos Maku" (Ibid.).

Danilo Ramos segue sua análise com algumas considerações sobre as pesquisas de Peter Silverwood-Cope com o grupo Bara-Maku (Kakwa), e de Howard Reid com os Hupd'äd. A conclusão geral desse percurso analítico pela literatura etnográfica maku é que os aspectos de mobilidade descritos por Koch-Grünberg definem

um modelo de natureza e cultura onde os Maku, dadas suas práticas, estão imersos na natureza e têm os Tukano como contraponto de cultura, devido aos seus costumes sedentários, rituais, normativos, linguísticos e habitacionais. Legitima-se a dominação de um povo pelo outro da mesma forma que se defende o avanço da cultura sobre a natureza, de sedentários sobre nômades (Id.: 82).

Já no caso de Reid e Silverwood-Cope, as práticas sociais dos Maku, imersas na natureza, vão moldando sua cultura através de uma mobilidade constitutiva. Em ambos os casos, "a mobilidade é descrita como um traço preponderante que emana seja da animalidade (natureza), seja da imersão ou de maior proximidade da natureza" (Ibid.). E qual a posição de Danilo Ramos em relação a essas formulações da literatura acerca dos Maku? A partir de experiências vividas mutuamente entre o pesquisador e seus interlocutores, afirma: 
forma', 'mobilidade vs. imobilidade', 'caos vs. ordem', 'simetria vs. assimetria', 'sedentário vs. nômade', buscando uma orientação não dicotômica ou tipologizante para descrever não as unidades de sentido ou a totalidade da 'cultura hup', mas as dimensões, as direções movediças percorridas pelos Hupd'äh ao longo de suas existências (Id.: 83).

Esse capítulo, vale destacar, constitui uma lição ao pesquisador antropólogo ao, por meio de uma fina análise de textos, mostrar como certos olhares/imagens sobre determinados povos vão se constituindo ao longo das gerações de pesquisadores. Ao pesquisador que inicia seus trabalhos, ao apropriar-se da literatura, cabe estar atento a essas imagens herdadas. Avancemos.

Em "Viagem à Serra Grande", segundo capítulo do livro, Danilo faz uma descrição de sua viagem com os Hupd'äh à referida serra, percebida como uma paisagem de mediação fundamental entre a vida e a morte. Nesse lugar central para o mundo vivido hupd'äh, os movimentos e gestos dos viajantes revelam um modo específico de interação com os elementos e seres ali presentes. Assim, atos como evitar beber água da Serra Grande, contar narrativas sobre o lugar, retomar a disputa com o padre e com os soldados, salientar a necessidade do retorno, a extração do curare, todos episódios descritos pelo autor ao longo desse capítulo, podem ser vistos como "ações ritualizadas que marcam um processo de condensação de modos de relação dos presentes entre si e deles com outros seres e com o ambiente onde interagiam" (Id.: 99).

Nesse capítulo, como em outros, Danilo Ramos operacionaliza de modo bastante competente as noções de paisagem e de educação da atenção de Tim Ingold. A viagem é descrita como educação da atenção e aquisição de habilidades. Assim, de acordo com o autor:

Compreendendo a observação desses caçadores-caminhantes como uma atenção ativa aos movimentos dos animais, e suas imitações como o alinhamento de sua atenção para seus próprios movimentos práticos para o ambiente, pode-se ter a dimensão de como esse andar coletivo envolve a todos num processo de aquisição de habilidades (Id.: 110).

No terceiro capítulo, "Círculos de coca", Danilo Ramos faz um levantamento das referências ao assunto na literatura. Em 1960, em sua enquete sobre os índios Maku do Caiari Uaupés para a Société Suisse des Américanistes, os irmãos Mário e Michel Terribilini descrevem o modo de preparo da coca. Na pesquisa de Reid, o consumo noturno de coca surge em meio a um relato de como se dá o trabalho dos Hupd'äh junto aos Tukano. A descrição desse autor delineia as rodas observadas na década de 1970 como uma forma de interação entre Hupd'äh e Tukano marcada pela assimetria, pelas trocas e pela prestação de serviços.

Um breve relato das rodas de coca é encontrado também em Peter Silverwood-Cope, feito em meio a uma análise sobre a integração dos grupos domésticos nos grupos locais. Esse trecho, segundo Danilo Ramos, apresenta elementos relevantes para entender a dinâmica das relações 
políticas, e como parece haver um senso de pertencimento ao grupo local que se reforça através das rodas de conversa. Dando continuidade a revisão bibliográfica, no trabalho de doutorado de Dominique Buchillet sobre os Desana, as rodas de coca são mencionadas em sua reflexão sobre o modo como o aprendizado de encantamentos e mitos se dá entre pai e filho por meio de diálogos cerimoniais. Já Christine Hugh-Jones, que fez pesquisa junto aos Barasana, detalha o processo de produção e consumo da coca em meio a uma descrição dos processos de produção dos alimentos. Stephen Hugh-Jones, por sua vez, enfoca o uso ritual e cotidiano da coca e outras substâncias pelos Barasana, através de uma minuciosa descrição dos hábitos de consumo da coca enquanto alimento masculino.

De forma muito próxima à análise de S. Hugh-Jones, Dimitri Karadimas aborda as concepções Miraña sobre o consumo cotidiano da coca. Em seguida, Danilo Ramos examina brevemente as análises de Sulkin, que em seu trabalho sobre os Muinane descreve a coca e o tabaco como substâncias importantes para as práticas rituais masculinas que envolvem o aprendizado de mitos e dos meios de proteção dos filhos e da esposa; o trabalho de Jacopin, que ressalta que os encontros noturnos de homens Yukuna iniciados para o consumo da coca e para a prática da palavra mítica constituem circunstâncias ritualizadas; e, por fim, comenta a tese de doutorado de Pedro Lolli, a qual apresenta uma excelente descrição das rodas de coca yuhup, mostrando suas relações com as práticas xamânicas desse povo.

Comer coca, fumar tabaco e conversar, nas análises de Danilo Ramos, são atos que parecem reunir os homens, particularmente os mais velhos, desses diversos povos descritos pelos pesquisadores. Esses atos delineiam também os contornos de uma modalidade específica de interação social e verbal. Além disso, "as interpretações apontam para certa comunhão e reforço da identidade local, para a diferenciação de papéis sociais e de gênero, para uma reciprocidade igualitária, para a mediação em relações assimétricas interétnicas, e para a realização de práticas xamânicas" (Id.: 139). O autor indica os trabalhos de Lolli, Jacopin, Sulkin e Karadimas como aqueles que delineiam essa forma específica de interação como constituindo um modo de ação ritualizada a partir de uma lógica relacional particular, o que permite enunciar sua posição analítica, já explicitada na introdução:

\footnotetext{
Procuro descrever as rodas de coca como uma performance, uma sequência reflexiva de ações verbais e não verbais, que possuem estilo, finalidades, retórica, padrão de desenvolvimento e papéis característicos. Ao mesmo tempo, busco enfocar a organização da ação performática nela mesma através da observação das interações entre diferentes seres e sujeitos em suas interagências (Id.: 139-140).
}

Por meio de uma descrição da preparação e formação das rodas de coca, bem como do benzimento da coca, Danilo Ramos tenta demonstrar como os processos e as relações das rodas de coca revelam uma performance, uma dinâmica constante de interações marcada por condensações 
rituais e por modificações na identidade dos participantes. As sequências, transformações, passagens entre as narrativas e eventos performáticos vão constituindo "transformações onde o interesse por ouvir, contar e ver gera aproximações e distanciamentos entre seres, pessoas, corpos e substâncias nos diversos tempos e espaços do cosmos através das viagens" (Id.: 183).

No quarto capítulo, "Círculos de fumaça", encontramos a descrição da caminhada a Serra da Cutivaia, de uma colheita de coca acompanhando o senhor Américo e análises das histórias contadas por Américo ao longo dessa viagem, nos percursos de ida e volta. A história da habitação da serra contada por esse senhor hup falava dos ancestrais e de suas ações de chegar ao morro e fazer dele suas moradas. A cada passo, afirma Danilo Ramos, "os mitos e as memórias emaranhavam-se nas falas de Américo. Compunham um modo de falar do pai, do irmão e de sua vida naquele ambiente que, aos poucos, temporalizava a paisagem" (Id.: 189). O capítulo segue com a exposição do mito sobre a dádiva da coca e do tabaco, uma descrição dos tipos de tabaco e seu plantio e os modos de preparação dos cigarros.

Em "Caminhos abertos", quinto capítulo, Danilo Ramos avança no exame da relação entre caminhos e benzimentos, mostrando como as ações do benzedor, em conjunção com ação de outros seres, geram mudanças num dado ambiente com o qual se relacionam. Descreve, para citar um momento do capítulo, a ação de Ponciano quando, às vésperas de uma viagem às serras para pescar e visitar os lugares sagrados, age de modo a afastar as nuvens de chuva. Segundo o autor:

Para que pudéssemos viajar para os morros e para as Moradas Antigas, o xamã alterou o rumo das nuvens da tempestade para cabeceira, fazendo com que os caminhos alagados secassem. Creio que essas múltiplas interações com as nuvens, de humanos e quelônios, sejam possíveis a partir da observação e da imitação, possibilitadas por processos de educação da atenção desses atores em seus ambientes (Id.: 254).

No sexto capítulo, "Lagos de Leite", Danilo Ramos volta sua atenção para o momento do nascimento de uma pessoa, e as ações envolvidas na manipulação do corpo do bebê. Descreve as práticas de proteção realizadas, como o "benzimento do filho", o qual é apresentado integralmente numa tradução para o português, seguido de minuciosa análise, que revela um qualificado conhecimento linguístico aliado à sofisticada sensibilidade etnográfica para os detalhes - as restrições alimentares e o manejo feito pelo xamã do "sopro vital", /hãwäg/, noção central no universo hup.

No sétimo capítulo, "Sopros na noite", Danilo Ramos oferece a descrição do ritual Jurupari e do Dabucuri, ou /Pä'/, na língua hupd'äh, mostrando de que maneira aspectos observados através do contínuo entre as rodas de coca e caminhos se relacionam com a sequência de ações do Dabucuri, "constituindo um campo de percepção e ação que diferencia e transforma as pessoas, definindo ou alterando as posições ocupadas por cada uma na performance e na sociabilidade da aldeia" (Id.: 412). Nesse capítulo, o autor revisa a teoria desses rituais elaborada pelo antropólogo inglês Stephen Hugh-Jones na década de 1970, a partir de sua pesquisa junto aos Barasana do rio 
Pirá-Paraná (Amazônia colombiana), afirmando que não parece haver uma divisão tão marcada entre a cerimônia do Jurupari e a troca de alimentos (Dabucuri, ou He Casa de Fruta) tal como descrita por Hugh-Jones, que formula esse último ritual como uma etapa do processo de iniciação, preparando a todos para o rito principal, o He Casa, uma grande cerimônia de iniciação marcada por ações masculinas que levam a uma apropriação simbólica das capacidades femininas de reprodução e menstruação para dar vida aos rapazes e transformá-los em adultos, membros do sib de descendência patrilinear (Id.: 412). Mais próximo ao que descreve Pedro Lolli para os Yuhupdëh do igarapé Castanha (também no rio Tiquié), Danilo Ramos sustenta que entre os Hupd'äh há ainda hoje "a alternância entre eventos em que as trocas rituais se somam à iniciação dos rapazes, e eventos em que ênfase recai sobre o oferecimento entre os parceiros, não sendo realizada a iniciação. Não se observa, portanto, uma relação de etapas entre as ações ritualizadas" (Id.: 412).

Por fim, no oitavo capítulo, "Viagens a São Gabriel", tal como o livro começa com a descrição da chegada a São Gabriel e a percepção do antropólogo que chega para pesquisa de campo, termina com a viagem de partida do pesquisador, que descreve o modo como os Hupd'äh percebem essa cidade, refletindo sobre como, através dessas viagens, "as pessoas hup movimentam-se pelos grandes rios, pelas ruas e pela escrita, transformando modos de percepção e ação a partir das posições que assumem em seus novos percursos orientados para a paisagem urbana" (Id.: 490).

A etnografia de Danilo Ramos, assim, contribui de modo competente para o aprofundamento da compreensão do mundo vivido hupd'äh, e desloca o olhar da literatura para o tema das rodas de coca, ao reposicionar e dimensionar sua importância na vida social hup. À guisa de conclusão, uma ressalva: é uma pena que a editora Hedra não tenha sido mais cuidadosa com as imagens, pois fotos e mapas aparecem em preto e branco, com resolução de baixa qualidade, algo que certamente pode ser apresentado de outra forma numa segunda edição. 